\title{
Knöcherner Zugang zur retrograden Nagelung am Humerus
}

\author{
Dankward Höntzsch
}

Es wird immer wieder berichtet, dass es beim retrograden Einbringens des Nagels am Humerus zu Frakturen des distalen Schaftes kommt.

Grund ist, dass der Eingang zu eng ist und dass die geometrische Form nicht stimmt, besonders am proximalen Ende des Fensters. Der Humerus ist dort sehr stabil und wenig elastisch und wenig tolerant auf Kräfte.

Es gibt verschiedene Anleitungen für das Eintrittsfenster (um nicht Urheberrechte zu verletzen in einfachen Zeichnungen vom Autor selbst gezeichnet).

Um nur zwei gängige Vorschläge zu nennen: Bohrlöcher in Dreiecksform mit Spitze in Richtung Schaft ( $\bullet$ Abb. 1 a) oder eine Bohrlochreihe ( $\boldsymbol{A} \mathbf{A b} \mathbf{b}$. $\mathbf{1} \mathbf{b}$ ). In allen Fällen wird danach relativ viel Fräsarbeit zum Erweitern nötig. Da verlässt viele die Geduld und die Sorgfalt - und schon passiert das Unglück.

Der Eintrittskanal muss auf der ganzen Länge so breit sein, wie der Nagel im Durchmesser ist ( $\bullet$ Abb. 2 und 3).

Das Fenster muss für das sehr flache Einlaufen lang genug sein. Circa 25-35 mm $\times 7-9 \mathrm{~mm}$ je nach Nageldurchmesser ( $\triangleright$ Abb. 2 und $\mathbf{3}$ ).

Distal sollte die Kortikalis am Fenster außen und proximal nach innen angeschrägt sein ( $\bullet$ Abb. 3 ).

Eine Alternative, um ein korrektes Fenster zu erreichen ist:

1. Bohren von 4 Löchern in den Ecken des geplanten Knochenfensters ( $\triangleright$ Abb. 2).

2. Zwischen den Löchern wird gesägt (eher nicht meißeln, wenn, dann sehr vorsichtig und wenn die Stege klein sind). Auf die Längsstrecke kann man auch noch ein Loch dazwischen bohren.

3. Mit nur wenig Fräsarbeit Anschrägen der distalen und proximalen Wand und Glätten der Ränder ( $\triangleright$ Abb. $\mathbf{3}$ ).

4. Der Fräser ist gleichzeitig ein Fühlen und Testen für den Einlauf des Nagels.
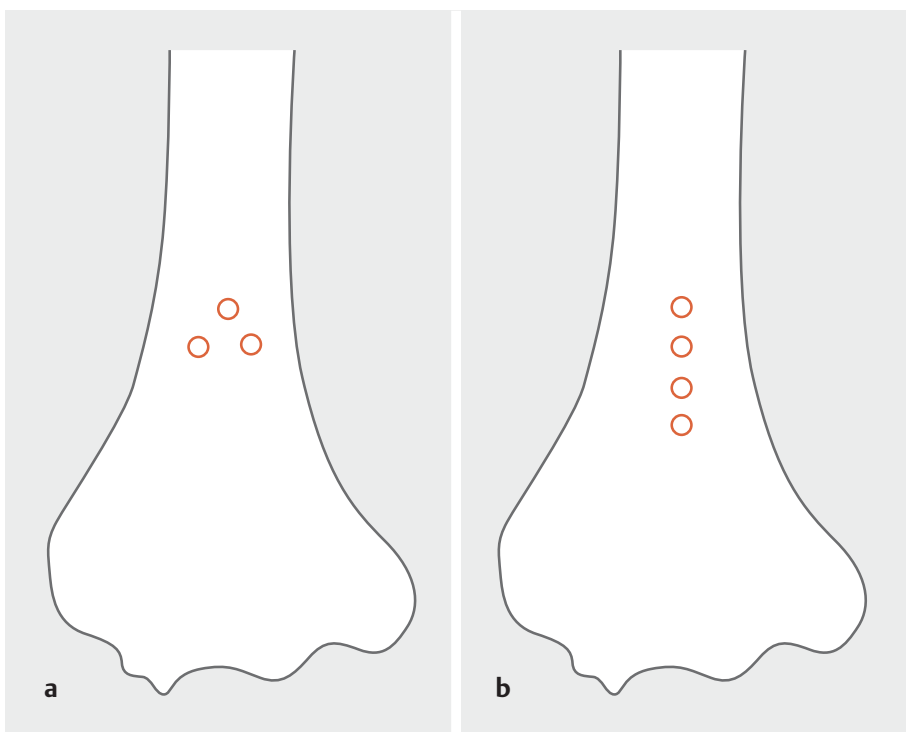

- Abb. 1 a Vorschlag von 3 Bohrlöchern mit nach proximal spitzem Dreieck, b Vorschlag für mehrere Löcher in einer Reihe.

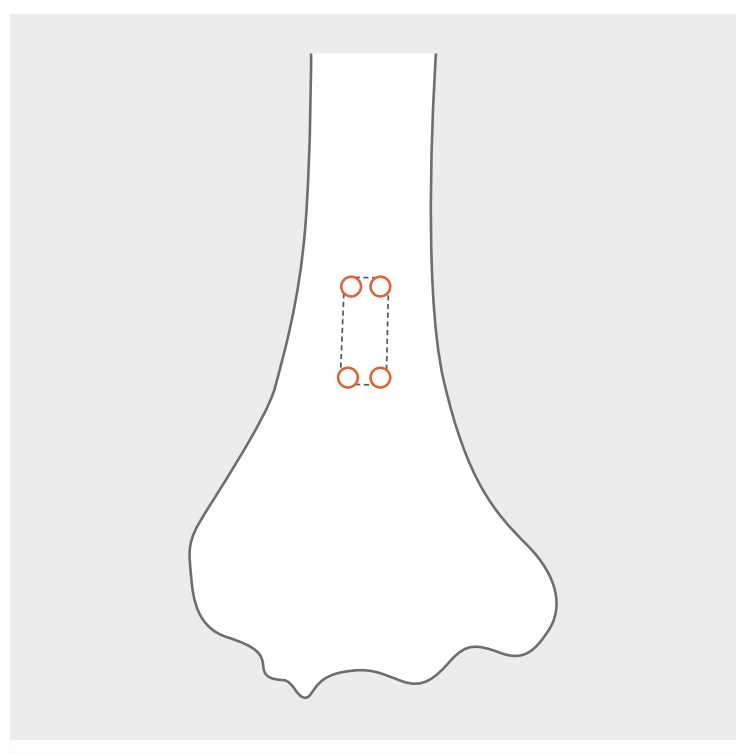

- Abb. 2 Alternative: 4 Bohrlöcher in den Ecken des notwendigen Knochenfensters zum Erreichen eines genügend langen und genügend breiten Fensters. 


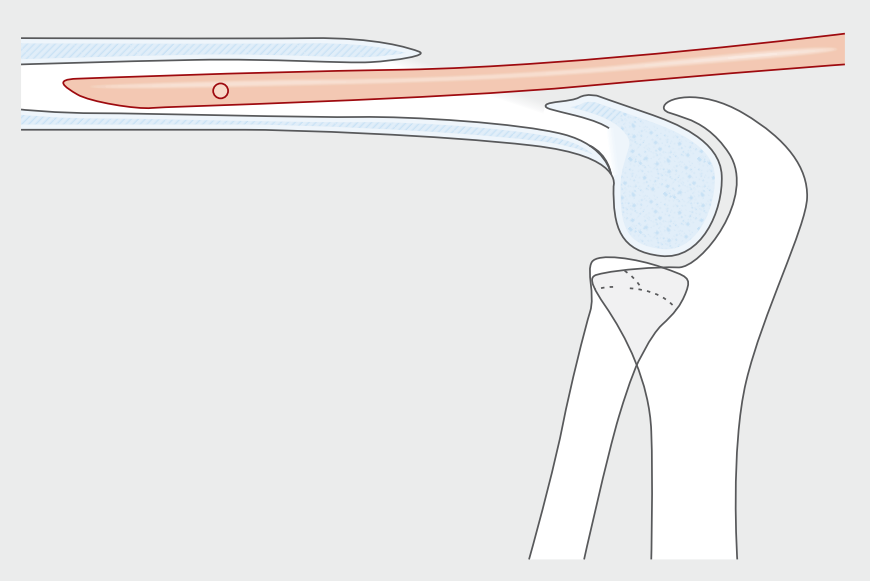

- Abb. 3 „Platzbedarf“ für das flache spannungsarme bzw. freie Einlaufen des Nagels in den Humerusschaft.
Rein handwerklich betrachtet ist dieses Verfahren besser definiert und führt rascher zu einem geometrisch korrekten Fenster.

Es ist ein von anderen Knochenfenstern bekanntes Verfahren.

Es dauert nicht länger, eher kürzer und ist sicherer.

Korrespondenzadresse

Prof. Dr. Dankward Höntzsch

Tübingen

hoentzsch@t-online.de

Bibliografie

DOI https://doi.org/10.1055/a-1031-5131

OP-JOURNAL 2019; 35: 347-348 @ Georg Thieme Verlag KG Stuttgart · New York ISSN 0178-1715 